\title{
Modeling the fine root biomass dispersion using a special influence function
}

\author{
Wälder $\mathrm{O}^{(1)}$, Wälder $\mathrm{K}^{*(2)}$ \\ This paper presents a successful application of techniques from the adjustment \\ theory for modeling interaction in fine root biomass dispersion. Using special \\ distance and species dependent weightings the influence function for fine root \\ biomass dispersion of two species is estimated. Using the estimated influence \\ functions the fine root biomass is predicted at the locations where the real \\ data was sampled. Goodness of fit of our model is evaluated by comparing \\ sample values and predicted values. However, the results show successful co- \\ incidence between sampled and predicted values. Finally, we present an ex- \\ ample for the root dispersion in a mixed stand of beeches and spruces in Sax- \\ ony/Germany.
}

Keywords: forest effects, fine root biomass, interaction, influence function

\section{Introduction}

Forest scientists as well as wood processing industry are interested in understanding and modeling interactions among trees in stands. The spatial distribution of the resource pool trees rely on affects the availability of these resources like water, nutrients and radiation for a tree. Now, such a characteristic as the fine root biomass depends on locations of the corresponding trees, their interactions and competition effects among them. Investigations of the spatial dispersion of the fine root biomass can contribute to an improved knowledge about these effects. In this paper, the multi-tree case with trees from two different species is discussed. At fixed locations at ground level we want to model the total mean of the fine root biomass in a fixed soil depth belonging to the trees from both species. Obviously, root dispersal is caused by the trees. The total biomass of fine roots consists of the contributions of the individual trees. Here, interactions can affect the root biomass. Therefore, we model the fine root biomass by a weighted sum of individual biomass contributions. Now, the fine root biomass meas

(1) Institute for Cartography, Technical University of Dresden, Mommsenstrasse 13, D-01062 Dresden (Germany); ${ }^{(2)}$ Institute for Stochastics, Freiberg University of Mining and Technology, Akademiestrasse 6, D-09596 Freiberg (Germany)

*Corresponding Author: Konrad Wälder (waelder@math.tu-freiberg.de).

Received: Apr 01, 2008 - Accepted: Oct 30, 2008

Citation: Wälder O, Wälder K, 2008. Modeling the fine root biomass dispersion using a special influence function. iForest 1 : 141-144 [online: 2008-11-25] URL: http://www.sisef.it/iforest urements should additionally be weighted related to the relative number of neighboring trees of the same species. This two-step weighting is necessary for modeling as well intra-specific interactions among trees of the same species as inter-specific interactions between different species. Obviously, our model can also be generalized for more than two species.

There are different mathematical methods for modeling interaction effects, see (Näther \& Wälder 2003, Näther \& Wälder 2006, Wälder \& Wälder 2008). In this paper, techniques of adjustment theory are taken into account.

\section{Material and methods}

\section{Study site}

The study was carried out in a mixed spruce and beech stand consisting of 11 beech (species 1) and 17 spruce trees (species 2) in Germany (Saxony) near to Dresden. The study site is part of a greater nearly homogeneous spruce stand. In 2003, soil cores were taken at 226 given sampling points with collections of the fine root biomass from the forest floor organic and mineral horizon, see Fig. 1 and Fig. 2.

Sampling procedure started with the collection of roots from the forest floor organic and mineral horizons using a steel frame (diameter $50 \mathrm{~mm}$ ). The samples per core hole (organic horizon, mineral soil up to a depth of $80 \mathrm{~cm}$ ) were filled in separated plastic bags. According to Böhm (1979) only roots $\leq 2 \mathrm{~mm}$ diameter are classified as fine roots. These roots were selected irrespective of their shape. Finally, the dead roots were separated. The distinction between living and dead components was made according to Murach (1984). Following separation, samples of live roots were oven-dried at

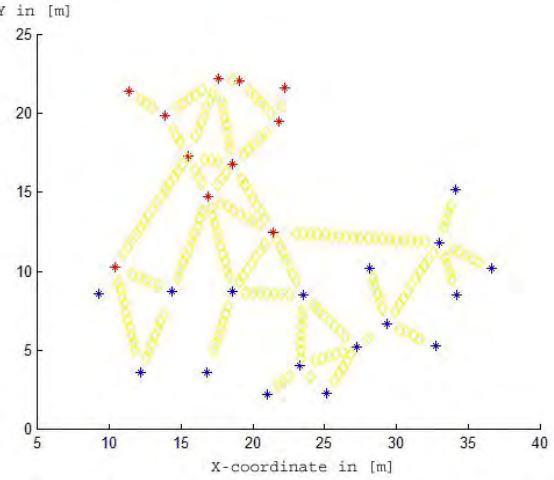

Fig. 1 - Locations of trees and fine root biomass measurements (transects) at the Rabenau site. The trees of the first species (beech) are colored with red stars. The trees of the second species (spruce) are colored with blue stars. Yellow diamonds show locations of measurements. Both axes $\mathrm{X}$ and $\mathrm{Y}$ are in [m].

$65^{\circ} \mathrm{C}$ for $96 \mathrm{~h}$. Mycorrhizae was not separated from root material.

In Näther \& Wälder (2006) an approach based on fuzzy theory is proposed for modeling inter- and intra-specific aggregations. In Näther \& Wälder (2003) a statistical model for dispersion effects based on cluster point processes is discussed. Ammer \& Wagner (2005) present an approach for modeling the mean fine root biomass of Norway spruce stands. Especially, they restricted themselves to modeling fine root biomass of one species. Here, we present an alternative method for modeling the fine root biomass distribution of two species. Techniques of the adjustment theory are used for our modeling.



Fig. 2 - Soil core from Rabenau. 


\section{Mathematical methods}

A deterministic alternative to the mark correlation function discussed in Wälder \& Wälder (2008) is the so called influence function defined in Wälder (2008). The utilization of tree individual-based models has been established in forest research and management for some years now. Analogously to the influence function many other models make use of the zone of influence ("ZOI" sensu Grimm \& Railsback 2005) approach; but they utilize this approach in very different ways (Yastrebov 1996, Okland et al. 1999, Saetre 1999, Kuhlmann-Berenzon \& Hjorth 2007). Now, such an influence function approach provides a simple method for interaction analysis and its advantage relies on its rejection of embarrassing restrictions which are necessary for stochastic methods: For example, it is well-known that not any function can be a correlation or a density function. Some conditions have to be fulfilled.

Let us explain the main idea of the influence function method based on an example from forestry. We assume that each tree characteristic, for example the fine roots biomass, depends not only on the corresponding tree, but also on other trees, namely on their locations and characteristics. It seems to be realistic to assume that this influence only depends on distances between measurement points of fine roots biomass and the tree. We denote the maximal tree distance with still existing influence $f$ with parameter $R$. Therefore, $f(r)=0, r>R$ holds. In our case study we use $R=10$ and $R=15[\mathrm{~m}]$. Now, we assume that this function $f$ is identical for all trees of the same species in a stand.

Further, we assume that there are two tree species with two different fine root biomass influence functions. The measurements of fine root biomass are taken around each tree following radial transect lines. The whole plot is divided into two groups: fine root biomass from trees of the first and of the second species, see Fig. 1.

The next model assumption refers to the linearity of the average of individual influences of neighboring trees for a fine root biomass value. Let $m^{j}$ be the fine root bio-

Tab. 1 - Some statistical characteristics providing goodness-of-fit of our model.

\begin{tabular}{|c|c|c|c|c|c|c|}
\hline $\mathbf{R}$ & Species & $\begin{array}{r}\text { Ob } \\
\text { meas }\end{array}$ & $\begin{array}{l}\text { erved } \\
\text { rements }\end{array}$ & $\begin{array}{c}\text { Values } \\
\text { estimated } \\
\text { with } m=5\end{array}$ & $m=7$ & $m=9$ \\
\hline \multirow{6}{*}{$10[\mathrm{~m}]$} & Species 1 & Mean & 60.9248 & 60.9561 & 60.8873 & 61.5880 \\
\hline & & Variance & $4.7628 \times 10^{3}$ & $1.7635 \times 10^{3}$ & $1.7387 \times 10^{3}$ & $1.8707 \times 10^{3}$ \\
\hline & & Correlation & 1.0 & 0.6152 & 0.6107 & 0.6395 \\
\hline & Species 2 & Mean & 97.2478 & 99.9726 & 98.3769 & 98.4068 \\
\hline & & Variance & $1.3658 \times 10^{4}$ & $0.7236 \times 10^{4}$ & $0.7660 \times 10^{4}$ & $0.8045 \times 10^{4}$ \\
\hline & & Correlation & 1.0 & 0.7513 & 0.7567 & 0.7712 \\
\hline \multirow{6}{*}{$15[\mathrm{~m}]$} & Species 1 & Mean & 60.9248 & 61.6426 & 61.9068 & 61.809 \\
\hline & & Variance & $4.7628 \times 10^{3}$ & $1.7532 \times 10^{3}$ & $2.0310 \times 10^{3}$ & $2.1523 \times 10^{3}$ \\
\hline & & Correlation & 1.0 & 0.6031 & 0.6575 & 0.6768 \\
\hline & Species 2 & Mean & 97.2478 & 100.317 & 98.61 & 98.794 \\
\hline & & Variance & $1.3658 \times 10^{4}$ & $0.7072 \times 10^{4}$ & $0.7729 \times 10^{4}$ & $0.7558 \times 10^{4}$ \\
\hline & & Correlation & 1.0 & 0.7297 & 0.7583 & 0.7522 \\
\hline
\end{tabular}

mass of species $j, j=1,2$, at point $x_{0}$. If $N$ neighboring trees are located at $x_{\mathrm{i}}, i=1, \ldots$, $N$, then we use the following approach assuming that all distances are smaller than $R$ (eqn. 1):

$m^{j}\left(x_{0}\right)=f^{j}\left(r_{01}\right) \cdot w\left(r_{10}\right)+\ldots+f^{j}\left(r_{0 \mathrm{~N}}\right) \cdot w\left(r_{N 0}\right)$ $r_{i 0}=\left|x_{i}-x_{0}\right|, \quad i=1, \ldots, N ; j=1,2$

$w\left(r_{i 0}\right)=\frac{1}{2 \pi r_{i 0}}$

The weights $w$ in eqn. 1 are necessary because the number of trees still increases with increasing distance. Now, these influence functions $f^{j}, j=1,2$ have to be estimated using the sampled fine root biomass values $m^{j}$. The estimator is denoted by $\hat{f}^{j}$. Our approach to solve this problem is based on techniques from the adjustment theory. At first, we restrict the number of unknown variables in eqn. 1. For example, for five values of the influence function this corresponds to the following locations:

$$
r_{k}=r_{\text {min }}+(k-1) \cdot \Delta, \quad \Delta=\frac{R}{4}, \quad k=1, \ldots, 5
$$

We should note that another number of unknown variables in (1) can also be considered. Tab. 1 presents the results for $m=5$,
7 and 9 in our case study. Setting

$$
\Delta=\frac{R}{m-1}, \quad m>1
$$

leads to $m$ values of $r_{\mathrm{k}}, k=1, \ldots, m$. Let us mention that an increasing number of unknown variables firstly results in an increasing estimation error and secondly in oscillations of the influence function estimator $\hat{f}^{j}$ caused by the relatively small number of trees at a fixed distance from a measurement. Thus, this restriction to only five (seven or maximal nine) variables seems to be useful and necessary. To take into account the stem diameter the parameter $r_{\min }>0$ is needed. Using seven or nine variables does not change the form of influence functions significantly, see Tab. 1. Thus, in eqn. 2 and eqn. 3 we use $m=5$ only in order to avoid overloading the given relations.

At second, each measurement $m^{j}$ should be weighted additionally. This weighting should mirror our confidence in the corresponding measurement. It means that the accuracy of a measurement $m^{j}$ (and in the same time our confidence) increases significantly, if there are only trees of the same species $j$. We denote these weights with $p$. Each weight should be proportional to the relative number


Fig. 3 - Fitted fine root biomass influence functions (Y-axis). The red lines correspond to the first tree species (beech). The blue lines describe the estimated influence function for the second tree species (spruce) for $k=5$ and $R=10[\mathrm{~m}]$ (a) and $R=15$ [m] (b). The X-axis represents the distance in $[\mathrm{m}]$. 
Fig. 4 - Fitted fine root biomass influence functions (Y-axis). The red lines correspond to the first tree species (beech). The blue lines describe the estimated influence function for the second tree species (spruce) for $k=7$ and $R=10[\mathrm{~m}]$ (a) and $R=15[\mathrm{~m}]$ (b). The $\mathrm{X}$-axis represents the distance in $[\mathrm{m}]$.
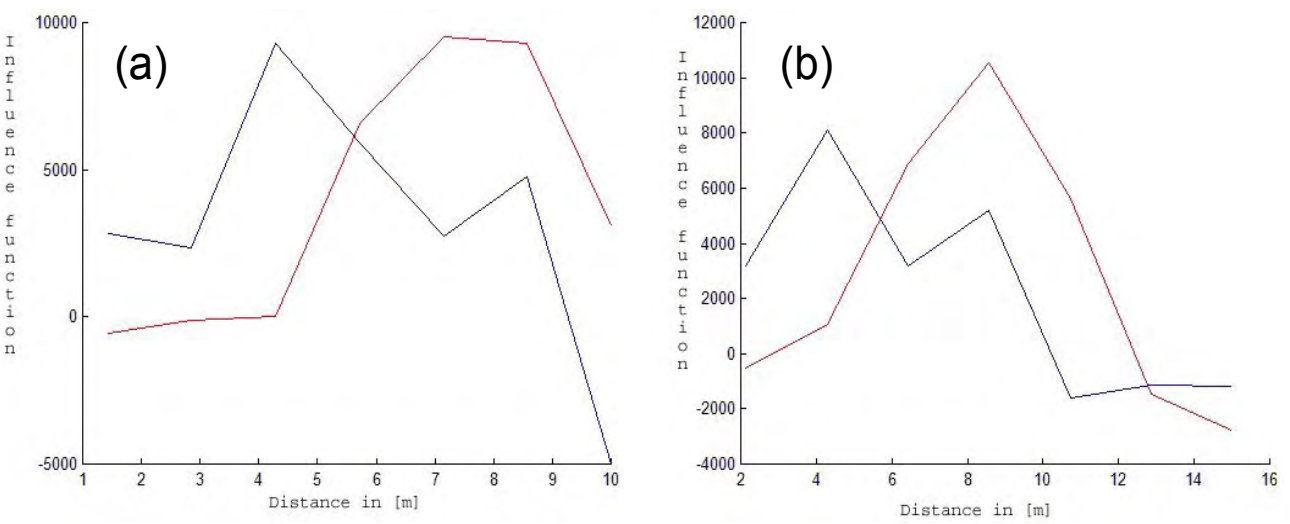

of trees of the same species the considered measurement of fine root biomass belongs to.

The solution of the following linear system of equations 2 which is well-known in the adjustment theory leads to the estimation $\hat{f}^{j}$ of the corresponding influence functions for both tree species $j=1,2$ (eqn. 2).

$$
\begin{aligned}
& \left\{\begin{array}{l}
X_{1}^{j} a_{1,1}^{j}+\ldots+X_{5}^{j} a_{1,5}=M_{1}^{j}+v_{1}^{j} \\
X_{2}^{j} a_{2,1}^{j}+\ldots+X_{5}^{j} a_{2,5}=M_{2}^{j}+v_{2}^{j} \\
\ldots \\
X_{n}^{j} a_{n, 1}^{j}+\ldots+X_{5}^{j} a_{n, 5}=M_{n}^{j}+v_{n}^{j}
\end{array}\right\} \Rightarrow A^{j} \cdot X^{j} \\
& \Rightarrow A^{j} \cdot X^{j}=M^{j}+v^{j} \\
& X^{j}: v^{j^{\prime}} \cdot P^{j} \cdot v^{j} \rightarrow \min , \quad j=1,2
\end{aligned}
$$

where $n$ is the number of measurements of fine root biomass denoted with $M$ for both tree species $j$, and (eqn. 3):

$$
\begin{aligned}
& X_{k}^{j}=\hat{f}\left(r_{k}\right), \quad k=1, \ldots, 5 \\
& A=\left(a_{l, m}^{j}\right), \quad a_{l, m}^{j}=\sum_{\forall r_{l}:\left|r_{m}-r_{l}\right| \leqslant \Delta / 2} w\left(r_{l}\right), \\
& P^{j}=\left(\begin{array}{lll}
p_{1}^{j} & 0 & 0 \\
0 & \ldots & 0 \\
0 & 0 & p_{n}^{j}
\end{array}\right)
\end{aligned}
$$

The elements of the matrix $A$ are cumulative weights which are defined in (1). The weights of all trees located at distances closer to the corresponding $r_{\mathrm{k}}, k=1, \ldots, 5$ should be summed up.

The exact solution of (2) corresponds then to (eqn. 4):

$$
X^{j}=\left(A^{j^{\prime}} \cdot P^{j} \cdot A^{j}\right)^{-1} A^{j^{\prime}} \cdot P^{j} \cdot M^{j}, \quad j=1,2
$$

\section{Results}

We applied the method described above for our data. From Fig. 3 and Fig. 4 it can be seen that the maximum of fine root biomass is different for both species. The maximum of fine root biomass for a beech yields approx. $5[\mathrm{~m}]$, while a spruce has this maximum at approx. $8[\mathrm{~m}]$. We restricted ourselves to $R=10[\mathrm{~m}]$ and $15[\mathrm{~m}]$ because of the small size of the observation window.
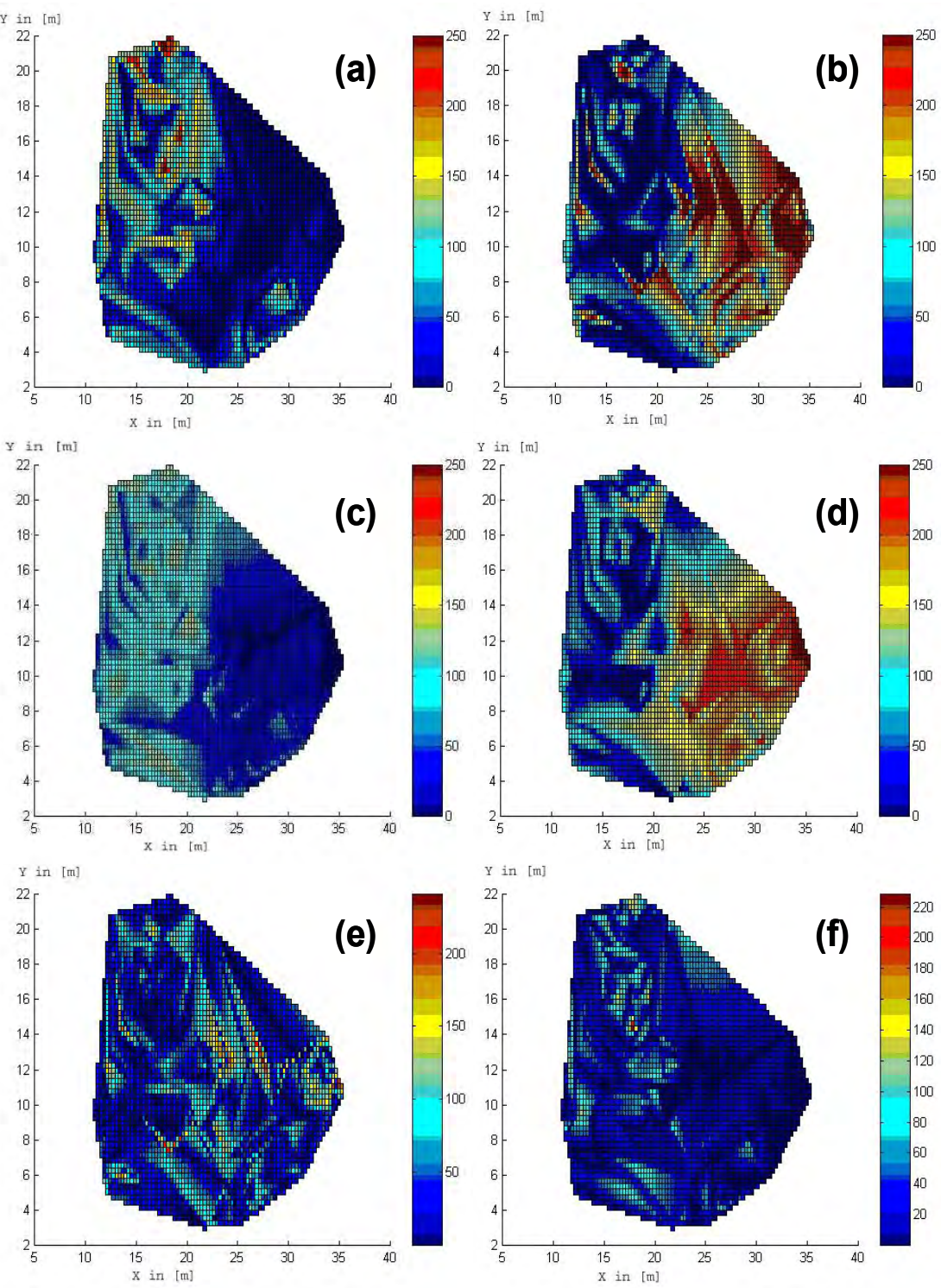

Fig. 5 - Real measurements of fine root biomass for the first species (a) and for the second species (b) at Rabenau. Estimated fine root biomass for the first species (c) and for the second species (d) for $k=5, R=15$ [m]. Absolute difference between observed and estimated values for the first species (e) and for the second species (f). Both axes X and Y are in $[\mathrm{m}]$. The color scale represents the fine root biomass in $\left[\mathrm{mg} / \mathrm{cm}^{3}\right]$. 
It should be noted again that using more than 5 variables does not change the form of the influence functions significantly. The corresponding results can be seen in Tab. 1 .

Fig. 3 and Fig. 4 show the estimated influence functions for some parameters. Fig. 5 presents the comparison between real and estimated values of fine root biomass for $k=5$ and $R=15[\mathrm{~m}]$. The linear interpolation method is used for visualization of the results in the observation window.

\section{Discussion}

In our paper we show that intra- and interspecific interaction and competition effects among trees and species can be modeled by a special two-step weighting approach. From an ecological point of view this is necessary because forest dynamics is shaped by suppression, support and survival of the strongest species.

In general, a mathematical model is a problem-related simplification and requires some restrictions and assumptions. Goodness-offit should be proved for each model. In our approach two influence functions are estimated. Based on them, the values of fine roots biomass are predicted at the locations where real measurements are given. The comparison of real (observed) and predicted (model) values is carried out calculating their means, variances and the correlation between real and model values. The obtained results underline that our model is well suited for describing the fine root dispersion in a mixed stand of two species.

\section{Conclusions}

Applying the influence function approach is very helpful, especially for such cases if additional restricting demands of other mathematical approaches could not be satisfied. For example, there are too small sampling sizes or vague measurements, etc. An influence function is free from restrictions: It can be as well positive as negative, it is not normalized. It is a simple and meaningful tool for a preliminary analysis of spatial multidimensional data.

Our approach provides a more general and flexible approach in comparison with the approaches by Näther \& Wälder (2006) and Ammer \& Wagner (2005). Differently from Ammer \& Wagner (2005) our model is not restricted to one species. The approach presented in this paper can even be generalized by using more than two species of trees. Differently from Näther \& Wälder (2006) our approach renounces strict statistical model assumptions.

Further, other tree-dependent characteristics, which are of interest for forest scientists, can be analyzed in a similar way. Therefore, we want to contribute to the broader dissemination of our approach in forestry and ecological research.

\section{Acknowledgements}

The authors are grateful to S. Wagner and A. Zeibig, who collected the root data we used.

\section{References}

Ammer C, Wagner S (2005). An approach for modeling the mean fine-root biomass of Norway spruce stands. Trees 19: 145-153.

Böhm W (1979). Methods of studying root systems. Ecological Studies vol. 33. Springer Verlag, Berlin, Heidelberg, New York.

Grimm V, Railsback SF (2005). Individual-based modeling and ecology. Princeton series in theoretical and computational biology. Princeton University Press, Princeton (USA).

Kuhlmann-Berenzon S, Hjorth U (2007). Accounting for large-scale factors in the study of understory vegetation using a conditional logistic model. Environmental and Ecological Statistics 14: 149-159.

Murach D (1984). Die Reaktion der Feinwurzeln von Fichten (Picea abies [L.]). Karst. auf zunehmende Bodenversauerung. Göttinger Bodenkundliche Berichte 77: 1-126.

Näther W, Wälder K (2003). Experimental design and statistical inference for cluster point processes - with applications to the fruit dispersion of anemochorous forest trees. Biometrical Journal 45: 1006-1022.

Näther W, Wälder K (2006). Applying fuzzy measures for considering interaction effects in root dispersal models. Fuzzy Sets ans Systems 158: 572-578.

Okland RH, Rydgren K, Okland T (1999). Singletree influence on understorey vegetation in a Norwegian boreal spruce forest. Oikos 87: 488498.

Saetre P (1999). Spatial patterns of ground vegetation, soil microbial biomass and activity in a mixed spruce-birch stand. Ecography 22: 183192.

Wälder K, Wälder O (2008). Analysing interaction effects using the mark correlation function. iForest 1: 34-38.

Wälder O (2008). Mathematical methods for engineers and geoscientists. Springer, Berlin, Heidelberg, New York.

Yastrebov AB (1996) Strength of tree phytogenic fields in Lichen-Green Moss Pine forests. Russian Journal of Ecology 27: 1-7. 